\title{
Marginalidad y vanguardia en la posguerra: los inicios del teatro crítico en Chile (1883-1913)/
}

\author{
Marginality and Postwar Avant-Garde: the Dawn \\ of the Critical Theatre in Chile (1883-1913)
}

\author{
Carlos Donoso Rojas
}

ORCID iD: http://orcid.org/0000-0003-0154-6446

Universidad de Tarapacá, Chile

\begin{abstract}
Nuestra investigación analiza las características definitorias de un formato teatral alternativo, surgido en Chile tras el término de la Guerra del Pacífico, paralelo al de los circuitos obreros y de sectores aristocráticos. Invisibilizado en su época, sin estar sujeto a presiones comerciales, o a la observancia de la crítica, su importancia debe dimensionarse tanto en su connotación testimonial, como por su aporte a la renovación de las artes escénicas nacionales. Estas se expresaron en el desarrollo de nuevas técnicas de representación $y$, en particular, en una profunda innovación a partir de la escenificación de lo cotidiano, sentando las bases del teatro social chileno.
\end{abstract}

Palabras Clave: Crisis moral; Dramaturgia; Chile; Historia cultural.

Our research analyzes the defining characteristics of a different theatrical format, which emerged in Chile after the end of the War of the Pacific, parallel to the working-class circuits and aristocratic groups. Almost imperceptible in its time, without being subject to commercial pressures or the approval of critics, it should be taken into account both in its testimonial connotation as well as its contribution to the renewal of the national performing arts. These were expressed in the display of new techniques of representation, and particularly, in a deep innovation, laying the groundwork for the subsequent development of the Chilean Social Theatre.

KEYwords: Moral crisis; Dramaturgy; Chile; Cultural history.

Copyright: (C) 2017 CSIC. Este es un artículo de acceso abierto distribuido bajo los términos de una licencia de uso y distribución Creative Commons Attribution (CC-by) España 3.0. 
La historia del teatro en Chile ha sido estudiada, preferentemente, desde perspectivas literarias, sin establecer vínculos definidos con la coyuntura social y política de sus ciclos de producción. ${ }^{1}$ Sobre esa base, existe consenso en que la actividad dramática, a partir del último tercio del siglo XIX, no tuvo mayor trascendencia, tanto en lo que respecta a la calidad de las obras como en el nivel de sus montajes.

Sin un hito temporal que permita suponer un nexo con la contingencia, diversas investigaciones han optado por consensuar el año 1890 como el año en que se inicia una nueva era en el teatro chileno (ligándola, aparentemente, al fin del antiguo orden político), cerrando el ciclo con la conmemoración del centenario de la independencia, un referente paradigmático en lo político que, para el caso de las artes escénicas, es irrelevante. De acuerdo con estos criterios, la irrupción de un nuevo Chile habría permitido el giro desde creaciones teatrales de menor valor hacia otras con un enfoque social crítico, desde donde emergieron las bases de la dramaturgia nacional. ${ }^{2}$

En ese contexto, la producción dramática del período se analiza, preferentemente, como parte de un proceso mayor de cambios en la sociedad chilena. Bernardo Subercaseaux, siguiendo a Raphael Samuel, sostiene que a fines del siglo XIX, con la ampliación y diversificación del universo simbólico, comienza la conformación de un circuito cultural de masas, orientado a un público de interés creciente y sensible a las demandas sociales y de mercado. Solo a partir de entonces, el teatro comenzó a entregar contenidos digeribles por los sectores medios y populares, transformándose «en un espectáculo cuyo propósito fuese, en definitiva, la gratificación inmediata o simplemente la diversión del espectador». ${ }^{3}$

En la misma línea, Eduardo Santa Cruz, ha propuesto lo que denominó «esfera pública plebeya», con formas, medios y espacios de formación de una identidad común, vinculada con un proceso de instalación de una cultura de masas emergente hacia fines del siglo XIX, que no fue excluyente para las artes escénicas. ${ }^{4}$ Esta postura, a su vez, avala la premisa de Grinor Rojo, quien años antes había dado cuenta del surgimiento, en ese entonces, de una estructura teatral definida como «el primer movimiento de modernidad en América Latina», esto es, un teatro europeo de importación y uno

1 Bravo y Munizaga, 1987, 31.

2 Piña, 2009, 16-31. Catalán, 1985, 72. Pradenas, 2006, 203-212.

3 Subercaseaux, 1988, 270-279. Samuel, 1985.

4 Santa Cruz, 2014, 23. 
profesional (integrados en función de su rentabilidad), y un teatro popular, de consumo masivo y sin pretensiones intelectuales. ${ }^{5}$

La distinción de Rojo en torno a formatos teatrales consolidados no es azarosa, reflejando, para el caso del popular, los prejuicios que diseñan la idea polarizada de la estructura dramatúrgica finisecular chilena. En efecto, además del teatro de la «alta cultura», el cambio de siglo se asocia, casi sin excepción, al teatro militante (entendido como aquel escrito por y para trabajadores, basándose en temáticas inherentes a su condición), identificable en Chile como político, anarquista, revolucionario o de redención, transformado en un medio para llevar cultura a sectores marginales y orientarlos ideológicamente. ${ }^{6}$ Desde este principio, en los últimos años se ha insistido en la continuidad de una dramaturgia ácrata, la que habría logrado un reconocido arraigo en sectores proletarios, manifestando, a través de él, una forma de resistencia cultural a un sistema excluyente. ${ }^{7}$

Es importante destacar que los rasgos definitorios del teatro militante, propuestos en estudios que acentúan su impacto en núcleos obreros (esto es, trabajar con códigos literarios propios, representar una realidad heterogénea y rescatar de la memoria las experiencias colectivas), son cualidades transversales del teatro chileno del período. Esto, sumado al cuestionamiento riguroso y asertivo planteado por Sergio Grez, ${ }^{8}$ respecto a la connotación más amplia de la postura ideológica del teatro aludido, reduce el impacto de la dramaturgia anarquista a un núcleo legítimo e influyente, pero de representación limitada en el espectro social de su época.

Como una característica que lo define, el teatro militante tampoco se centra espacialmente en el mundo urbano, situándose, en cambio, en el mundo de las salitreras o el ámbito rural, y solo de modo marginal en las ciudades, aludiendo al migrante que busca una mejor calidad de vida. ${ }^{9}$ En contraste, los registros de obras que aluden a temáticas obreras siguen siendo escasos para el período que precede al año 1913, y su relevancia se enmarca, fundamentalmente, en el ascendiente moral de autores como Juan Rafael Allende, Luis Emilio Recabarren y Antonio Acevedo Hernández. ${ }^{10}$ Llama la atención que, a juicio de este último, considerado el precursor de la dramaturgia social en Chile, la transformación del teatro hacia un

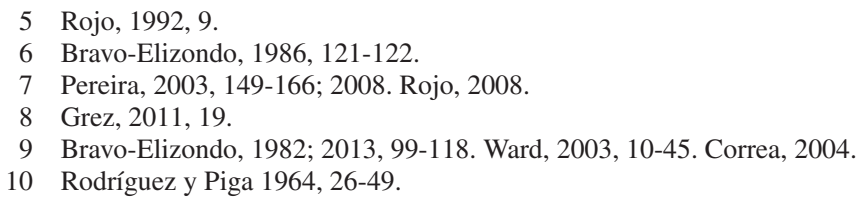


discurso reivindicativo la iniciasen autores como Víctor Domingo Silva, Aurelio Díaz Meza y Juan Manuel Rodríguez, identificados en los albores de siglo XX con la sátira y el drama urbano. ${ }^{11}$

La insistencia en tomar al costumbrismo o al naturalismo como elementos basales del teatro militante de las últimas décadas del siglo XIX, no permite distinguir variables temáticas con interpretaciones complejas, caracterizadas por una dinámica de conflictividad, evidenciable incluso en comedias. Así, la evolución del teatro chileno se reduce a la imposición de modelos políticos y culturales hegemónicos, definidos en torno a símbolos abstractos, como el patriotismo enardecido, la idea de unidad, y la simpleza de la narración de costumbres. ${ }^{12}$

La difusión de estas ideas y principios se encuadraba en la propuesta de construcción del concepto de lo nacional, que condicionó la evolución de la dramaturgia en buena parte de las nacientes repúblicas del continente, haciéndola parte de la fuerza cultural dominante del período en estudio. El teatro paraguayo resaltó la figura del personaje corriente, como un elemento clave de la reconstrucción nacional tras la guerra de la Triple Alianza (1864-1870), rescatándolo en su heroicidad, pero también en elementos prehispánicos que definieron una simbiosis cultural hasta hoy reconocible. ${ }^{13}$ En México, en los primeros años del porfiriato se generó un activo debate respecto a la necesidad de promover el teatro con obras, actores y directores locales, y temáticas que aludiesen a valores, espacios sociales y modelos reconocibles como nacionales. ${ }^{14}$ En Brasil, el «teatro moralizador» o «civilizador», surgido tras el término de la monarquía, se basó en el rescate de lo cotidiano, enfocándose en la representación del mundo popular. Desde esa perspectiva, la dramaturgia (con apoyo estatal) se orientó a las masas, transformándose en una efectiva herramienta de integración cívica, que facilitó la transición a la república. ${ }^{15}$

El teatro latinoamericano, a partir del último tercio del siglo XIX, propuso la representación de sujetos activos y constituyentes de las nacientes repúblicas, heterogéneos con sus conflictos y contradicciones que, desde espacios marginales, enunciaban un mensaje de lo que eran y a lo que aspiraban. De este modo, la cultura de los sectores marginales y medios en

11 Acevedo Hernández, 1982, 52-61.

12 Souriau, 1950, 38-55. Salaün, 2001, 131.

13 Sant'Anna, 1987, 40-52.

14 Conway, 2003, 148-149.

15 Silva, 2013. 
los incipientes estados nacionales se transformó, a través de las artes dramáticas, en una práctica articuladora, formativa e integradora. Como fenómeno histórico, la dramaturgia tuvo el mérito de poner en escena a sectores excluidos, minimizados o satirizados, transformándose en un espejo de las necesidades simbólicas del receptor en cada momento histórico. ${ }^{16}$

En Chile, en cambio, el teatro se alejó de los preceptos básicos que definían los discursos asociables a principios raciales, eugenésicos o nacionalistas, recurrentes en ensayos y estudios sociológicos del período. ${ }^{17}$ Si bien se reconocen excepciones, la dramaturgia chilena se estructuró en torno a elementos culturales distantes a esos cánones, y no llegó a constituirse en un instrumento manipulable como estrategia de legitimación política. $^{18}$

La vía propia desarrollada por un sector del teatro chileno, en las últimas décadas del siglo XIX, evidenció un claro compromiso social, pero sin una identidad arraigada en discursos oficiales o de clase. Esto ha sido interpretado como una postura ambigua, lo que justificaría su contribución poco significativa al desarrollo cultural del país. ${ }^{19} \mathrm{Su}$ limitada relevancia, a su vez, minimizó su posterior apreciación crítica, reduciendo su análisis al contenido ideológico de su propuesta (esto es, con un mensaje político preciso y unívoco), diferenciándolo de las artes escénicas triviales, como la lírica, la zarzuela y el drama europeo, que no pretendían asimilar la realidad de su entorno como propia. Como señala Juan Villegas, mientras uno postulaba como un rango definidor de su código estético, el carácter intransable de la belleza y la calidad del teatro, el otro aspiraba a realizar con él solo una función práctica educativa. En ambos casos, se daba por sobreentendida la idea de una relación absoluta de la verdad, o al menos la convicción de que «su razón» merecía ser erigida como modelo. ${ }^{20}$

En un contexto donde el concepto de lo no burgués se asimilaba a la clase proletaria, la escasa importancia dada al emergente teatro crítico no supone su inexistencia, sino su invisibilidad para la memoria oficial de la historia de la cultura y del teatro. ${ }^{21}$ Tratándose, por tanto, de modos de representación disímiles en formas y contenido a la dramaturgia tradicional,

16 Pelletieri, 1989, 180-181. Pedraza, 2005, 157-160.

17 Gazmuri, 2001, 7-20. Subercaseaux, 2010. Sánchez, 2015.

18 Balandier, 1994, 15-44. Bryan, 1983. Rubio, 1989.

19 Orrego, 1927, 17-18. Morgado, 1943, 14-17.

20 Villegas, 1997, 138. Pronko, 1969, 97.

21 Una excepción, en Ochsenius, 1982, 5-6. 
su estudio debe realizarse a partir de la comprensión de patrones y definiciones propios que dan cuenta de su particularidad. ${ }^{22}$

Indistinta a las temáticas que aborda, y a las coyunturas temporales que enfrenta, durante al menos treinta años se gestó en Chile una tercera vía de desarrollo teatral, que se caracterizó por ser marginal y austera, pero inserta en un mercado cultural en continuo crecimiento, dispuesto a absorber influencias foráneas. Fue un movimiento de vanguardia genuino, sin pretensiones de profesionalismo ni organización reconocible, que promovió una ruptura consciente de los «estilos formales», creando tipos y prácticas que adquirieron una importancia creciente para el orden social. ${ }^{23}$ Su estructura y objetivos asemejaban al Theâtre Libre de André Antoine en Francia (1887), o la Freie Bühne de Otto Brahm en Alemania (1889), creados como una plataforma al drama realista, ${ }^{24} \mathrm{y}$ a las condiciones propuestas en el Théâtre du Peuple de Romain Rolland y Maurice Pottecher, quienes, a inicios del siglo XX, se apartaron del teatro burgués, creando uno popular con argumentos basados en la experiencia.

Rolland sugería una dramaturgia que representase la rudeza de lo cotidiano, pero alejada del diletantismo aleccionador. La moralidad de su modelo teatral se insertaba en una mirada del género como «una luz para la inteligencia», orientado a poner en escena vivencias significativas para la audiencia, invitándola a reflexionar a través de la dramatización de sus propias experiencias..$^{25}$ Pottecher, al igual que Rolland, apoyaba un teatro no propagandístico sino uno formativo, diferenciándose en que este debía destinarse a pequeñas audiencias, dispuestas a asimilar un mensaje que forjara una identidad y formación cívica en torno a un pasado común que rescatar e imitar. ${ }^{26}$

Aunque parezca anacrónico, el teatro crítico chileno del cambio de siglo, que apostaba por la economía de medios escénicos, privilegiando la intensidad de la interpretación, se aproxima al modelo parateatral (Tercer Teatro) como el sugerido por Eugenio Barba (1995). Este funcionaba en la periferia de los circuitos tradicionales, con sus propios modos de producción y de edición, ocupando espacios improvisados y actuando para un público reducido. Sin trasfondo comercial, pudo probar formas de representación

22 Obregón, 2000, 69-70. Pavis, 1992, 17.

23 Williams, 1981, 77-78.

24 Oliva y Torres, 2014, 298-300. Bouchardon, 2009.

25 Rolland, 1953, 94-96. Castagnino, 1981, 111-113.

26 Carlson, 1993, 316- 317. 
originales, lo que impulsó técnicas de actuación y dirección innovadoras, arriesgando puestas en escena experimentales que insinuaban la decadencia de la sociedad. ${ }^{27}$

Fue, en esencia, un teatro en que lo dominante era el criterio de la verosimilitud. No buscaba la agitación política, sino la representación de una realidad asociable a sectores marginales, que postulaba, a través de él, sus inquietudes y valores. Es, en todos los casos, un modelo único, una manifestación divergente y paralela a las estructuras clásicas que se insertan entre lo popular y lo político, antecediendo formas de teatralidad que, a mediados de la década de 1910, se radicalizaron hacia un compromiso social exacerbado, en particular cuando ideas integradoras, como la de nacionalidad y raza, fueron definitivamente validadas y asimiladas por la elite intelectual chilena. ${ }^{28}$

\section{Los albores del teatro crítico}

Durante la Guerra del Pacífico (1879-1883), la dramaturgia chilena experimentó un florecimiento excepcional, asumiendo un papel clave al alimentar un imaginario simbólico y estético, mediante argumentos simples que sirvieron para involucrar en el conflicto a una población mayoritariamente analfabeta. El teatro surgido de esa contingencia supuso un interesante cambio en el paradigma de la dramaturgia chilena, hasta entonces orientada a mostrar espacios aristocráticos o de sectores emergentes. El teatro patriótico, en contraste, encumbró a personajes comunes que, a partir de episodios relevantes, representaron un ideal de moralidad transversal de los chilenos, sin distinción de género ni posición social. ${ }^{29} \mathrm{Si}$ bien perduró solo durante la vigencia de la guerra, su estructura trascendió el conflicto, orientándose, desde entonces, a criticar el establishment político y denunciar la progresiva crisis valórica.

El nuevo estatus de la dramaturgia nacional fue una respuesta a las profundas transformaciones derivadas del cambio en las bases estructurales de un Estado en crecimiento inorgánico y, en especial, con la ampliación del mercado cultural derivada de ese proceso. A diferencia de lo que ocurrió en países como México, Perú o Argentina, donde existía una tradición

27 Watson, 1987; 2015.

28 Cordua, 2007, 138.

29 Donoso y Huidobro, 2015. 
dramática previa y se consolidaron tempranas propuestas orientadas hacia sectores populares, ${ }^{30} \mathrm{su}$ desarrollo en Chile surgió a partir de la conformación de un circuito marginal y paralelo a la denominada «alta cultura» y al creado por organizaciones obreras.

El teatro crítico, además de poner en escena una realidad identificable para el espectador, se forjó limitado espacial y materialmente, al margen de la crítica literaria y con una mínima difusión en medios de prensa tradicionales. Influenciado por autores españoles como Jacinto Benavente, Benito Pérez Galdós y, en especial, José Echegaray, el nuevo formato dramático logró un profundo arraigo en sectores urbanos, a partir de la puesta en escena de conflictos irreconciliables donde el protagonismo del chileno, siempre apasionado y virtuoso, se enfrenta a un antagonista intrínsecamente perverso. Dicho rol, asignado en el teatro patriótico a militares peruanos y bolivianos, se traspasó al término de la guerra a la clase política, asumiendo un discurso que buscó poner de manifiesto las profundas contradicciones socio-económicas de la época. ${ }^{31}$

La abundante producción teatral en el período (estimamos una existencia total de alrededor de doscientas obras publicadas entre 1883 y 1913) sigue siendo desconocida, fundamentalmente, por la omisión de la prensa tradicional y de la crítica literaria de su época, desinteresada en difundir, y menos valorar, cualquier esfuerzo de proyecciones estéticas alternativas a la de sus respectivos círculos. Mientras en países como España o México la recurrente teatralización de sectores marginales en la época ha sido interpretada como un intento de los grupos intelectuales por evitar ser desplazados de sus privilegios, en Chile lo que se percibía era un abierto desprecio hacia ellos. En 1888, un crítico literario, aludiendo a la producción teatral independiente de su época, se preguntaba por qué existían autores y actores que insistían en dedicar todo su tiempo y recursos a obras que nadie escuchaba, juzgaba, aplaudía o pagaba. ${ }^{32}$

El juicio peyorativo apuntaba a cuestionar, a priori, los estándares de la producción nacional, una actitud que formaba parte de una idea preconcebida de lo que debía entenderse por cultura. El recurrente arribo a Chile de compañías líricas francesas e italianas, o de zarzuelas españolas, y la excepcional visita de figuras de reconocimiento mundial, como Rafael Calvo

30 Salaün, 1995, 176.

31 Donoso y Huidobro, 2016, 9-21.

32 Rubio, 1989. Beverly, 2004, 185-212. Covarrubias, 1888, 125. 
en 1885, Sarah Bernhardt en 1886 o Clorinda Pantanelli en 1894, dejó claro que la «alta cultura» estaba reservada para un segmento muy limitado. ${ }^{33}$

Así también lo entendían los emergentes sectores medios. En 1889, el diario La Época, orientado a ese segmento, definía a la zarzuela como «un jénero anfibio repleto de retruécanos de dudosa moralidad». Mucho más concluyente era la impresión sobre las representaciones líricas y lo que representaban:

La ópera lírica no es espectáculo para el hombre de trabajo, porque, en primer lugar, es espectáculo caro, a propósito solo para las grandes fortunas, i, en segundo lugar, irá mas que a oir música i a ver vistosos trajes i hermosas decoraciones, toda vez que se canta en un idioma que le es extraño... Por otra parte, muchos de los dramas líricos, mas que enseñanzas de moral, son un tejido de crímenes que deben dañar el corazón del pueblo.

Dejemos el teatro lírico para la jente rica que lo puede pagar i para la jente instruida que con su instrucción se teje una coraza, no siempre invulnerable a los tiros del escándalo melodramático. ${ }^{34}$

La distancia y la distinción de la elite para con lo inferior evidenció el profundo desconocimiento de la existencia de circuitos culturales alternativos, y condicionó la posibilidad de congregar en el teatro a las muchedumbres integrales, según Pérez Galdós, donde asistiese «desde el ser refinado que mucho sabe y poco siente hasta el analfabeto que ignora todo y siente con poderosa intensidad». ${ }^{35}$ En noviembre de 1888, un mitin organizado por el Club del Progreso, una sociedad integrada por «hombres liberales y jóvenes estudiosos» de Santiago, concluyó que en Chile no existía un arte genuinamente nacional. El problema, de acuerdo con la opinión mayoritaria, pasaba por la ausencia de «sentimiento artístico del pueblo» y la falta de un carácter propio, definido por factores culturales y raciales, que distanciaba a la sociedad chilena de las naciones civilizadas. Es interesante constatar que la única voz disonante en la reunión plantease que la causa de que no hubiese arte y cultura de calidad debía buscarse en un argumento más sencillo: la arraigada costumbre de subestimar las producciones nacionales. ${ }^{36}$

33 Varela, 1889, 275-277.

34 La Época, Santiago, 21 de junio de 1889, 3.

35 Citado en Salaün, 2001, 132.

36 Revista de Artes y Letras, XV, Santiago, 1889, 275-288, 3. 
Un ejemplo del prejuicio de parte de determinados sectores se evidenció en 1902, con el estreno de la ópera Lautaro, de Eliodoro Ortiz de Zárate. Formado en el Real Conservatorio de Milán y reconocido como uno de los principales autores líricos chilenos, Ortiz de Zárate logró estrenar su obra en el Teatro Municipal de Santiago, un espacio entonces reservado para una aristocracia que vio en el montaje «una afrenta a su noble tradición». ${ }^{37}$ Tras un breve período de ensayos, Lautaro fue presentada el 7 de agosto, siendo vilipendiada por la prensa tradicional, y también por la obrera, que rechazaba toda forma de representación del modelo político o económico que no supusiese una idea de regeneración implícita. ${ }^{38}$ Un crítico teatral (que inicialmente valoró Lautaro como una pieza solo regular), centraría con posterioridad su análisis en la imposibilidad de desarrollar el teatro en Chile, a partir de la recurrencia de juicios arbitrarios que precedieron la crítica:

Lo ocurrido con Lautaro ya es suficiente para que, en lo sucesivo, ningún artista se atreva a llevar sus producciones al teatro. Aquí, donde se considera una infamia el hecho de que un hombre se atreva a demostrar en público sus conocimientos sobre tal o cual ramo, donde hai cien mil pigmeos dispuestos a colgarse de los pies de quien tenga la osadía de querer subir, no es caso de estrañarse que el señor Ortiz de Zárate no haya sido apedreado en público.

En Chile para surgir es indispensable empezar por negar la nacionalidad i hacerse rodear de todos esos doctores que dispensan sonrisas i favores, no al mérito i la modestia, sino a los buenos apellidos. ${ }^{39}$

Lautaro era la primera parte de la trilogía patriótica La Araucana, sin que Ortiz de Zárate alcanzase a estrenar las restantes. Al no poder cubrir los costos del montaje, el músico terminó solicitando una subvención al Senado para continuar su carrera en Europa. ${ }^{40}$

El «prurito de causticidad» de los literatos y críticos chilenos hacia temáticas nacionales, denunciado tempranamente por el filólogo Rodolfo Lenz, ${ }^{41}$ quedó de manifiesto con la sobrevalorada comedia Don Lucas Gómez o un huaso en Santiago, de Mateo Martínez Quevedo. Presentada por primera vez en 1885, hasta su quinta edición, de 1894, había vendido sobre treinta mil ejemplares y se había representado en más de doscientas ocasiones, por distintas compañías, a lo largo del país. Su enorme e inesperado

37 El Diario Ilustrado, Santiago, 23 de julio de 1902, 7.

38 El Defensor de la clase proletaria, Iquique, 10 de noviembre de 1902, 3.

39 El Entre-Acto, Santiago, 12 de agosto de 1902, 67.

40 Cámara de Senadores de la República de Chile. Sesión Extraordinaria n. ${ }^{\circ}$ 23, 15 de noviembre de 1902, 496.

41 La Lira Chilena, 49, Santiago, 1904, s.p. 
éxito le ha valido, hasta hoy, ser considerada como una pieza de referencia para identificar el teatro popular chileno del cambio de siglo.

Con rasgos próximos al teatro bufo español o al tardío grotesco criollo argentino (hay notables similitudes con la adaptación teatral de Juan Moreira, de Eduardo Gutiérrez, de 1886), ${ }^{42}$ narra la difícil inserción del protagonista homónimo, en el entorno de su enriquecido hermano residente en Santiago. Gómez, proveniente de un sector rural próximo a la capital, confronta con picardía a un grupo familiar aristocrático que, ridiculizado en sus formas y expresiones, resulta funcional para destacar su carácter ladino. La deformación del personaje de Lucas Gómez convierte la obra en una confrontación implícita entre civilización y barbarie, donde abunda la risa fácil por medio de diálogos simples que no apuntan a una problemática específica que le dé sentido, sino a resaltar el carácter del personaje erigido, por contraste con los secundarios, en el eje de la trama.

En un medio en donde existía la convicción de que los trabajadores urbanos no tenían ilustración ni gusto intelectual, Don Lucas Gómez pareció ser una genuina aproximación popular al teatro, al combinar elementos dramáticos con elementos circenses (baile, música y demostraciones de habilidades físicas), que formaban parte constituyente del gusto masivo. En febrero de 1893, un editorial del periódico El Porvenir, titulado «Pensemos en el pueblo», advertía, precisamente, que el circo era el único medio de moralizar a las masas trabajadoras, al ser, probadamente, el espacio de sociabilidad que las alejaba de los vicios:

El obrero no halla en que gastar sus días i sus horas de descanso. Los elevados goces del espíritu, los placeres del arte, de la sociabilidad i el lujo no están a su alcance. La plática cuotidiana [sic] con los suyos no le satisface: se lanza a la calle en busca de algún entretenimiento i de la compañía de amigos i camaradas: tropieza con el bodegón, i allí, a la embriaguez, la crápula i las pendencias, dilapida el fruto de su trabajo i el pan de su familia... ${ }^{43}$

Don Lucas Gómez simbolizó un modelo de representación teatral que se ajustaba a ese discurso: sin pretensiones estéticas, de consumo fácil, y sin más intención que divertir mediante la burla emanada de diálogos incongruentes. El objetivo de poner en escena un personaje cuyo oponente fuese un orden social que lo condenaba al fracaso, y ante el cual respondía con astucia, se reiteró en una vasta producción literaria orientada a los

42 Golluscio de Montoya, 1984, 143. Legrás, 2002, 54.

43 El Porvenir, Valparaíso, 4 de febrero de 1893, 4. 
sectores populares, aludiendo a acciones sencillas, de carácter verosímil y diálogos animados. ${ }^{44}$

En el teatro, sin embargo, el retrato del chileno astuto y pícaro no tuvo continuidad alguna. Una posterior obra de Martínez Quevedo, La mujer de don Lucas Gómez (1895), escrita en la misma línea de su predecesora, fue un fracaso comercial. En contraste, piezas contemporáneas que por su título permiten suponer la secuencia de una sátira liviana, eran en realidad creaciones complejas, con un trasfondo siempre explícito. El roto en las elecciones, de Carlos Lathrop (1898), presentada como un juguete cómico, se centra en la angustiante espera de un candidato a diputado en la víspera del día de votación. Ilusionado con ser elegido al Congreso para tener un ingreso con que pagar las deudas que lo tenían al borde de la ruina, recurre al electorado campesino, ofreciéndoles comida y alcohol. La banalidad de la clase política es tan evidente en la obra como la superficialidad de los votantes, representados en escena como un liberal, un radical y un conservador, quienes, no obstante sus diferencias, están dispuestos a favorecer con su voto al mejor oferente.

El roto en las elecciones es una obra amarga, que evidencia la profunda crisis moral de un sistema político envilecido por la riqueza del salitre. La decadencia institucional del país, exacerbada tras la guerra civil de 1891, se reiterará con particular crudeza en la producción teatral de fines de siglo, a través de la representación de personajes oscuros, críticos de una nación a la deriva. El ya aludido Martínez Quevedo advertía en Los comediantes políticos en vísperas de elecciones (1896) que su obra, lejos de replicar el molde de Lucas Gómez, buscaba exponer «una crítica espiritual i verídica de las malas artes i costumbres que se ejercitan con nuestros ciudadanos en las elecciones, por los partidos i los políticos aventureros que esplotan nuestro atraso social, cubriendo sus ambiciones con un falso oropel de patriotismo mentido i embustero». ${ }^{45}$

El teatro crítico reflejaba una realidad, no planteaba reivindicaciones ni aspiraba a un cambio mayor de la sociedad, recurriendo a la alegoría y la fuerza simbólica implícita en ella. Sin amor y por dinero, de Juan Francisco Ureta (1885), vuelve sobre la trama costumbrista de la familia aristócrata, habitual en el teatro nacional antes de la Guerra del Pacífico, esta vez empobrecida e incapaz de asimilar su ruina. En tono de comedia, el esfuerzo del grupo por conservar las apariencias y ocultar el drama que los avergonzaba,

44 Cornejo, 2013. Palma, 2006. Salinas, 2004.

45 Martínez Quevedo, 1905, 5. 
denota un conflicto moral tan profundo como el de aquellos que, en la obra, los ridiculizan una vez conocida su mísera realidad. La República de Jauja, de Juan Rafael Allende (1889) es, por su parte, una fina parodia en donde se confrontaban las virtudes cívicas (La Verdad, La Democracia y El Trabajo) con los intereses gremiales y económicos ligados al sistema político (La Aristocracia, El Presupuesto, La Industria). Escrita como una crítica contra el gobierno de José Manuel Balmaceda (Camaleón II), fue censurada tras su primera representación, en donde La Verdad apareció literalmente desnuda, un gesto que, en la época, no se comprendió en un sentido simbólico.

El teatro chileno de postguerra puede definirse como uno «que centraba su atención en el drama humano surgido de estructuras sociales injustas y que buscaba, a la vez de sacar a escena a sectores marginados, investirlo de los derechos que le son inherentes». ${ }^{46}$ Exceptuando a Don Lucas Gómez, incluso cuando se recurre a la comedia, los protagonistas eran expuestos como sujetos conflictuados, insertos en un contexto de decadencia material y espiritual que incomoda al lector o espectador, pero a la vez lo seduce e identifica. Platicando (1899), comedia firmada por Juvencio, propone un diálogo entre dos chilenos y un visitante uruguayo, a quien buscan convencer de la pretendida superioridad cultural chilena, en un diálogo inteligente y lleno de ironía que trasunta la pobreza intelectual del país. De igual modo, El cuento del tío (1904), comedia del aludido dramaturgo Juan Rafael Allende, ambientada en Santiago del año 2000, involucra desde campesinos hasta ministros de Estado, en una trama absurda de ambiciones y engaños que denuncia, con lucidez, la crisis moral de inicios de siglo.

\section{Moldeando la vanguardia}

Salvo un número acotado que alude a principios ideológicos definidos —el drama Suprema Lex, de Rufino Rosas (1895), es reconociblemente anarquista, y el monólogo Don Pascal Guerra, de Marcos de la Barra (1899), asume un papel ideológico explícito al identificarse como socialista-, el teatro del período 1883-1913 se presenta crítico del sistema político y económico, el que exacerbaba el abatimiento del habitante urbano o del migrante rural. Los personajes, casi sin excepción, sufren por los abusos y la carestía, ante una realidad que los inmovilizaba. El castillo de naipes, de

46 García Pavón, 1962, 18-19. 
Armando Hinojosa (1909), revisa en tres actos la historia republicana de Chile, desde la opulencia lograda por el salitre hasta su decadencia a inicios del siglo XX. Es una sátira agria, que se centra en criticar la pasividad de los sectores populares al tolerar, en plena crisis, la continuidad de una clase política corrupta, carente de una visión de Estado.

Sin esperanza en el futuro, no es extraño constatar cómo la decadencia que cada personaje trasunta se asimila a la de la patria, socavada por el descrédito y la inmoralidad. Fuese escenificada como mujer (Javiera Carrera en Luis Carrera o la conspiración de 1817, de Pedro Urzúa, 1883; o Críspula en Fuera de su centro, de Antonio Espiñeira, 1887), niño (Huérfano!, de Juan Rafael Allende, 1890), o como un joven común (Redención o El grumete del Cochrane, de Teodosio Martínez Ramos, 1912), la patria fue un elemento recurrente en el teatro crítico, ejerciendo el rol de una superestructura, que le confería sentido a la acción de los representados.

Un caso paradigmático es La Mendiga, de Ricardo Fernández, estrenada en mayo de 1888. La obra entrega una trama clásica centrada en las desventuras de Mercedes, una mujer de pasado aristocrático que, tras la muerte de su esposo, se ve forzada a vivir en la calle. Mercedes es auxiliada por dos jóvenes, que viven en la casa de Pablo, su antiguo amor, a quien dejó elegir las comodidades ofrecidas por su difunto esposo. La Mendiga destaca por el tenso y pasional diálogo entre Mercedes y Pablo, cuya fuerza dramática vislumbra, desde una particular perspectiva, la paradoja social del Chile de su época. En estricto rigor, Mercedes y Pablo simbolizan a la patria en dos períodos próximos en el tiempo. Pablo, descrito por Mercedes como «virtuoso, feliz y amante», representa al Chile anterior a la Guerra del Pacífico, cuya pureza se ve enfrentada al envilecimiento causado por la ambición material. Mercedes, aludiéndose como una mujer que «quería ser tan rica como lo soñaba», simboliza en su matrimonio por conveniencia la dependencia chilena del salitre, y las consecuencias de su efímera riqueza.

El arrepentimiento de Mercedes no fue razón suficiente para obtener el perdón de Pablo, quien, además de despreciarla, la culpa por destruir sus convicciones, sumiéndolo en una crisis moral que lo transformó en un ser escéptico. La Mendiga finaliza con la muerte de su protagonista, en una escena que hace suponer su asesinato. El crimen, sin embargo, no tuvo un sentido expiatorio: el dolor de Mercedes aparenta más el sufrimiento resultante con una condición no prevista, que la culpa por el dolor provocado a Pablo. Enfrentado a la superficialidad de su antiguo amor, este enloquece en medio de una horrible tormenta que alude a su desvarío. 
La transfiguración de la decadencia nacional, a través de representaciones simbólicas, puede entenderse como un proceso de transición hacia la búsqueda de una necesaria renovación valórica de la sociedad. Sin apuntar al cambio del modelo político, esta idea denota el distanciamiento del teatro de figuras reconocibles, y que tanto la narrativa como la historiografía finisecular destacaban como determinantes en el proceso de formación republicana.

Salvo casos aislados que tomaron la figura de Arturo Prat, un joven capitán de marina que, tras su muerte heroica a inicios de la Guerra del Pacífico, se erigió en Chile como modelo de virtud cívica, la producción teatral del período optó por rescatar a personajes reconocibles, pero de segunda línea, cuyos méritos comprobables eran menos excepcionales que lo que simbolizaban. La puesta en escena de la vida del último gobernador español en Chile, de un paradójico Alonso de Ercilla patriota, de una distintiva mujer del siglo XVII, o del guerrillero independentista Manuel Rodríguez, lograron crear expectativas que se reflejaron en un particular éxito de taqui1la. Paralelamente, la representación de un pasado idealizado a partir de la simbiosis entre la herencia española con la sabiduría indígena fue exaltada en piezas como La ciudad encantada de Chile, de Jorge Klickmann (1892), presentada como un drama patriótico-histórico-fantástico, y en el rescate de dos referentes del pueblo mapuche, como el aludido Lautaro, Caupolicán, o la reivindicación de caciques araucanos personificados en hombres de esfuerzo. $^{47}$

\section{Consideraciones finales}

La historiografía chilena ha dado cuenta de una falta de atención hacia la cultura popular y los sectores medios desde el siglo XIX, reflejando su relativización, principalmente por parte de los sectores ilustrados de la sociedad chilena. ${ }^{48}$ Esta representaba los cánones de un sistema que se asumió como válido para generalizar los intereses colectivos, apartando a otras expresiones paralelas al consenso preestablecido por la tradición. Desde esta perspectiva, no se ha cuestionado en profundidad qué ocurría a nivel de prácticas cotidianas con los sujetos marginados del análisis, y tampoco

47 El Padre Padilla, Santiago, 7 de noviembre de 1895, 3. El Entre-Acto, Santiago, 12 de agosto de 1902, 7.

48 Catalán, 1985, 87-89. Tala, 2011. 
sobre el potencial existente en sus contenidos para desarrollar un proyecto cultural alternativo. ${ }^{49}$

La invisibilidad de la dramaturgia crítica, inserta en el contexto de desprecio hacia manifestaciones culturales de menor valía, fue consecuencia de la irradiación de la «civilización europea moderna», que tenía en el teatro, como género y espacio material, uno de sus elementos más identitarios e imitables. ${ }^{50}$ La idea de modernidad implícita en ella también apuntaba a dimensionar los alcances de la actividad dramática en cuanto a su trasfondo comercial y, ciertamente, en las expectativas que generaba. En 1888, un crítico recordaba que, independientemente del valor abstracto de la idea de arte, todas las manifestaciones de la actividad humana estaban sometidas a la ley económica de la oferta y la demanda. Esto no excluía a la producción intelectual, condicionando la libertad creativa a elementos subjetivos y de compleja evaluación, como la calidad y el gusto del público. ${ }^{51}$

Estos factores estaban directamente relacionados con la restringida demanda de espectáculos teatrales del período. Un cronista, al cuestionar la ausencia de «un teatro de temáticas nacionales», se preguntaba si existía en Chile un número suficiente de dramaturgos y actores para impulsarlo. Bajo el supuesto de que efectivamente los había, su duda era si estos podían fidelizar al público con temáticas variadas y de calidad, para satisfacer sus exigencias, de modo tal de crear una demanda continua. Su conclusión fue negativa:

Aunque tengamos autores dramáticos y aunque los actores sean de primer orden y la censura no deje nada que desear, nos falta la vida literaria y el amor al arte en la sociedad. Nos falta el ambiente en que la dramática nacional puede desarrollarse y prosperar. Pasado el primer entusiasmo, como la atmósfera que nos rodea no es propicia para el drama, nos faltarían los actores y después los autores y volveríamos á quedar como estábamos y con un desengaño más. ${ }^{52}$

La aparente decadencia de las artes dramáticas nacionales tenía componentes adicionales a considerar, que no tenían relación directa con la imposición hegemónica de una idea de cultura. El pago de derechos por propiedad intelectual fue regulado en Chile solo a partir del año 1925. Hasta entonces, la publicación de obras literarias y teatrales extranjeras careció de

49 Barr-Melej, 2003. Yeager, 1991. Silva Avaria, 2008.

50 Hurtado, 2007.

51 Covarrubias, 1888, 126.

52 Revista de Artes y Letras, XII, Santiago, 1888, 106. 
todo tipo de control, favoreciendo la temprana difusión de textos clásicos. Entre 1885 y 1889, la Imprenta y Librería Americana reprodujo libremente obras de Shakespeare, Cervantes, Flaubert y Dumas, entre otros autores, en ediciones de bajo costo. Su dueño, Carlos Lathrop, también incluyó en su catálogo a autores españoles, como Francisco Camprodón y José Echegaray, y editó un número significativo de zarzuelas, alterándolas y reconociendo, en algunos casos, solo los créditos de autoría musical. ${ }^{53}$ No existían mayores objeciones frente a ello: en 1889, un autor consideraba que el mayor anhelo de un literato era que se le tributase en el extranjero el honor de traducir o editar sus escritos, pues, salvo excepciones, «nuestra literatura está en principio i, por tanto a menester de estímulo progresar». A su juicio, un autor extranjero no tendría por qué sentir lo contrario. ${ }^{54}$

Desde la perspectiva del empresario teatral, la idea de financiar el montaje de una pieza teatral extranjera y de reconocido interés era más viable que la de arriesgar recursos por una producción nacional, que implicaba un pago al autor y sobre la que pesaban prejuicios de origen. El Expósito, de Fernando Muriel Reveco (1892), una obra extraordinaria que se presentaría en el teatro Politeama en diciembre de 1893, fue retirada del programa al no tener espectadores en su primera función. ${ }^{55}$

Sin capacidad para afrontar la competencia, sujeto a la crítica parcial, o al nulo apoyo del público, el teatro de creación chilena cayó en un prematuro descrédito. Esto también explica que entre 1894 y 1904 se representasen solo tres obras líricas de doce escritas y publicadas por autores chilenos en el período. Algunos teatros particulares, levantados en Valparaíso y Santiago entre 1886 y 1901 para montar espectáculos populares, no lograron continuidad y cerraron al poco tiempo. Otros, como el Santiago o el Romea, que intentaron innovar ofreciendo obras por tandas (muy comunes en México y Perú), fueron denunciados por círculos conservadores como «antros de paganismo»y «escenarios de inmoralidad i bajas pasiones». ${ }^{56}$

Hacia el cambio de siglo, el teatro como espectáculo debió enfrentar nuevos elementos asociados a la modernidad, y que le restaban el interés público. Las peleas de gallos y, en particular, las corridas de toros, prohibidas desde el inicio de la República, siguieron gozando de popularidad en

53 La Lira Chilena, Santiago, 6, 1899, s.p.

54 El Moscardón, Santiago, 28 de marzo de 1889, 3.

55 La Escena, Santiago, 5 de diciembre de 1893, 5.

56 Boletín de Actas y Documentos de la Ilustre Municipalidad de Santiago, 1894, 262. La Opinión, Santiago, 22 de octubre de 1894. La Nueva República, Santiago, 28 de enero de 1899, 3. 
sectores populares y medios, ante la inacción de las autoridades. El «añejo i sangriento espectáculo de la Edad Media», ${ }^{57}$ denunciado reiteradamente por la prensa, se complementó con la irrupción del boxeo y el fútbol, transformándose en prácticas culturales insertas en lo que Norbert Elias denominó «proceso civilizador», asociadas a nuevos mecanismos de autocontrol social. ${ }^{58}$

El reemplazo del teatro como medio de esparcimiento se confrontó, de modo decisivo, con la irrupción del cine. A partir de la primera proyección cinematográfica en Chile, en agosto de 1896, gran parte de las salas del país fueron adaptadas como biógrafos. En 1913, se registraban 51 locales destinados al cine en Santiago, y solo el Teatro Municipal seguía orientado a representaciones líricas y teatrales. ${ }^{59}$

La dramaturgia tradicional chilena, entendida como comedias de costumbres, zarzuelas y sainetes, hasta los años veinte se sumió en un período de decadencia. Esto hizo que la escena nacional se mantuviese monopolizada por compañías dramáticas extranjeras, fundamentalmente españolas e italianas, relegando las presentaciones nacionales a espacios reducidos o improvisados, pensadas para pocos actores (excepcionalmente, Certamen Nacional Chileno, de Carlos Lathrop, 1894, puso a 36 personajes en escena) y publicadas en editoriales o imprentas menores, creando un circuito paralelo al tradicional. Víctor Domingo Silva, uno de los principales referentes teatrales de la primera mitad del siglo XX, inició su vida en escena actuando en la comedia Por la Patria (1899), de Onofre Avendaño, presentada en la Sociedad de Sastres de Santiago. Arturo Bührle, precursor del teatro profesional chileno, actuaba en obras nacionales montadas en una carpa junto a la Vega Central, un popular mercado del centro de la capital. Juan Pérez Berrocal, protagonista de los primeros largometrajes nacionales, recordaba sus comienzos representando piezas de contenido crítico, actuando en el patio de casas y en centros obreros y parroquiales a lo largo del país. ${ }^{60}$

Como una paradoja a considerar, la diversificación de medios de esparcimiento, que condicionó el desarrollo de la dramaturgia formal chilena, validó la proliferación de espacios teatrales populares, con obras que confrontaban el imaginario de bienestar creado por el cine y el deporte,

57 Ecos Teatrales, Santiago, 15 de enero de 1900, 6.

58 Elsey, 2011, 20.

59 Santa Cruz, 2005, 206-207. Villarroel, 2012, 10.

60 Sienna, 1933, 34. Pérez Berrocal, 1980, 13. 
en su función evasora. En 1912, el reconocido crítico Pedro Nolasco Cruz advertía la existencia de un circuito teatral paralelo a la «alta comedia», refiriéndose a él — sin identificarlo directamente- como un medio válido para renovar un sistema de producción teatral chileno a partir de repertorios literariamente más ambiciosos, sostenido por actores identificados con sus personajes, no reactivos a las exigencias del público. ${ }^{61}$

La crítica que sostenía la elite intelectual respecto al «otro teatro», esto es, a su falta de profesionalización y la precariedad material de las representaciones, se transformó en un sello distintivo de un género destinado, en esencia, a denunciar sin asociarse a discursos reivindicativos. El dramaturgo Benjamín Morgado, que inició su carrera teatral presentando piezas de crítica social, defendía el sentido «puro y arcaico» del teatro, distante del facilismo tradicional:

El teatro aficionado, por su misma condición de masa obrera, por el hecho de estar más en contacto con el hombre que no espera nada de nadie, sino en su propia reivindicación, su propio mejoramiento, tiene un contenido social que nadie había querido tocar en el teatro [...] El teatro aficionado debería terminar de una vez por todas con el drama de la niña que el galán abandonó cuando iba a ser madre, para hacer un teatro eminentemente depurado y sociológico, donde hubiera un latido, una esperanza, una puerta abierta hacia el futuro de nuestra clase explotada. ${ }^{62}$

El carácter del teatro crítico chileno fue mutando en la medida que la crisis social y económica se profundizó, a la vez que comenzaba a ser permeado por posiciones ideológicas definidas, transformándose, desde inicios de la década de 1910, en un efectivo foro político y de discusión de ideas. Como ha propuesto María de La Luz Hurtado, a partir de entonces su conexión con la contingencia implícita contribuyó a generar espacios de identidad colectiva en los sectores más pujantes, combativos y autoconscientes del momento. ${ }^{63}$

Las transformaciones impulsadas por el teatro crítico, en función de la coyuntura histórica del período, permiten establecer un nexo directo con la aparición, en 1913, de la Compañía Dramática Nacional, la primera instancia formal creada para mostrar un repertorio chileno con intérpretes locales, bajo criterios comerciales. ${ }^{64}$ La formación de la Compañía coincidió con el estreno, ese año, de Un hombre, de Adolfo Urzúa Rozas (1911, publicado

61 El Diario Ilustrado, Santiago, 2 de agosto de 1912, 9.

62 Morgado, 1943, 10.

63 Hurtado, 2011, 36.

64 Bravo-Elizondo, 1982, 100-101. 
en 1914), y La vuelta de héroe, de Braulio Rodríguez López (1912), dos piezas que representan, con una simple crudeza, la decadencia de un país envilecido a partir del triunfo en la Guerra del Pacífico, y los profundos conflictos que derivaron en los años que siguieron a la Revolución de 1891. La publicación y montaje de estas piezas, seguidas de un apasionado debate asociado a la crisis social de su época, a nuestro juicio, marcan la transición hacia un teatro que, desde entonces, asumirá un discurso abiertamente confrontacional, abriéndose a opciones ideológicas inclusivas. De este vínculo emergerá, a inicios de los años veinte, el Teatro Social Chileno, un género literario en sí mismo, cuya influencia en el desarrollo de la dramaturgia nacional se extiende hasta hoy.

Recibido el 11 de abril de 2016 Segunda versión el 25 de octubre de 2016 Aceptado el 3 de noviembre de 2016

\section{Referencias bibliográficas}

Acevedo Hernández, Antonio, Memorias de un autor teatral, Santiago, Editorial Nascimento, 1982.

Balandier, Georges, El poder en escenas. De la representación del poder al poder de la representación, Barcelona, Paidós, 1994.

Barba, Eugenio, The Paper Canoe: a guide to theatre anthropology, London, Routledge, 1995.

Barr-Melej, Patrick, «Sowing "Seeds of Goodness" in Depression-Era Chile: Politics, the "Social Question" and the Labor Ministry's Cultural Extension Department», The Americas, 59, IV, 2003, 537-558.

Beverly, John, Subalternidad y representación. Debates en teoría cultural, Madrid, Iberoamericana, 2004.

Bouchardon, Marianne, «Du Panorama-Dramatique au Théâtre-Libre: le rôle du dispositif panoramique dans l'invention de la mise en scène moderne», Revue des Sciences Humaines, 294, 2009, 91-100.

Bravo, Anne y Munizaga, Giselle, «Contexto histórico y del espectáculo en Chile», (MS), 1987. Disponible en Biblioteca de Teatro, Pontificia Universidad Católica de Chile.

Bravo-Elizondo, Pedro, «El teatro obrero en Chile», Araucanía, 17, 1982, 99-107.

Bravo-Elizondo, Pedro, Raíces del teatro popular en Chile, Guatemala, Impresos D \& M, 1986.

Bravo-Elizondo, Pedro, Teatro y cultura socialista en Chile. Norte Grande, 19001934, Santiago, Ariadna Editores, 2013. 
Bryan, Susan E., «Teatro popular y sociedad durante el Porfiriato», Historia Mexicana, 33, I, Ciudad de México, 1983, 130-169.

Carlson, Marvin, Theories of the Theatre. A Historical and Critical Survey from Greeks to the Present, Cornell, Cornell University Press, 1993.

Castagnino, Raúl, Teorías sobre texto dramático y representación teatral, Buenos Aires, Editorial Plus Ultra, 1981.

Catalán, Gonzalo, «Antecedentes sobre la transformación del campo literario en Chile entre 1890 y 1920», en Brunner, José Joaquín y Catalán, Gonzalo, Cinco estudios sobre cultura y sociedad, Santiago, FLACSO, 1985, 69-175.

Conway, Christopher, «Próspero y el teatro nacional: encuentros trasatlánticos en las revistas teatrales de Ignacio Manuel Altamirano, 1867-1876», Iberoamericana, III, 9, Berlín, 2003, 147-159.

Cordua, Carla, «Nacionalismo y cultura», Revista Chilena de Literatura, 71, Santiago, 2007, 135-140.

Cornejo, Tomás, «Hablando con su excelencia: diálogos de impugnación política en La Lira Popular», Cuadernos de Historia, 39, Santiago, 2013, 7-32.

Correa, María José, «Candilejas pampinas sobre arte y expresión obrera: 19001920», Apuntes de Teatro, 125, Santiago, 2004, 71-80.

Covarrubias, Luis, Estudios críticos, Santiago, Imprenta de «El Progreso», 1888.

Donoso Rojas, Carlos y Huidobro Salazar, María Gabriela, «La Patria en escena: el teatro chileno en la Guerra del Pacífico», Historia, 48, I, Santiago, 2015, 77-97.

Donoso Rojas, Carlos y Huidobro Salazar, María Gabriela, Teatro chileno de la Guerra del Pacífico. Estudio preliminar, selección y notas, Santiago, Universidad Andrés Bello, Fondo Nacional de Desarrollo Científico y Tecnológico, 2016.

Elsey, Brenda, Citizens \& Sportmen: Fútbol \& Politics in 20th-Century Chile, Austin, University of Texas Press, 2011.

García Pavón, Francisco, El teatro social en España (1895-1962), Madrid, Taurus Ediciones, 1962.

Gazmuri, Cristián, El Chile del centenario, los ensayistas de la crisis, Santiago, Instituto de Historia, Pontificia Universidad Católica de Chile, 2001.

Golluscio de Montoya, Eva, «Del circo colonial a los teatros ciudadanos: proceso de urbanización de la actividad dramática rioplatense», Cahiers du monde hispanique et luso-brésilien, 42, París, 1984, 141-149.

Grez, Sergio, «¿Teatro ácrata o teatro obrero? Chile, 1895-1927», Estudios Avanzados, 15, Santiago, 2011, 9-29.

Hernández, Roberto, Los primeros teatros de Valparaíso y el desarrollo general de nuestros espectáculos públicos, Valparaíso, Imprenta San Rafael, 1933.

Hurtado, María de la Luz, «Actores europeos en los teatros de la Belle Epoque chilena: discursos locales en torno a modernidad, identidad y género», Apuntes de Teatro, 129, Santiago, 2007, 100-135. 
Hurtado, María de la Luz, Dramaturgia chilena 1890-1990: autorías, textualidades, historicidad, Santiago, Frontera Sur Ediciones, 2011.

Legrás, Horacio, «La cultura popular argentina de cambio de siglo: elementos para una nueva evaluación», Revista de Crítica Literaria Latinoamericana, 55, Medford, 2002, 53-72.

Martínez Quevedo, Mateo, Don Lucas Gómez: juguete cómico en dos actos y en prosa, Valparaíso, Imprenta de Julio Neuling, 1894 [1885].

Martínez Quevedo, Mateo, Los comediantes políticos en vísperas de elecciones: a propósito cómico-sanitario-político en un acto y en prosa, Santiago, Imprenta de E. Miranda, 1905.

Morgado, Benjamín, Eclipse parcial del teatro chileno, Santiago, Ediciones Senda, 1943.

Obregón, Osvaldo, «El teatro del pueblo de Romain Rolland y la resurgencia de sus ideas sobre el teatro popular en América Latina», en Obregón, Osvaldo, Teatro latinoamericano. Un caleidoscopio cultural (1930-1990), Perpignan, Presses Universitaires de Perpignan, 2000, 67-81.

Ochsenius, Carlos, Teatros universitarios de Santiago: el Estado en la escena 1940-1973, Santiago, CENECA, 1982.

Oliva, César y Torres Monreal, Francisco, Historia básica del arte escénico, Madrid, Cátedra, 2014.

Orrego Vicuña, Eugenio, Del nacionalismo en el teatro chileno, Santiago, Ediciones Cultura Social, 1927.

Palma Alvarado, Daniel, «"La ley pareja no es dura”: representaciones de la criminalidad y la justicia en la lira popular chilena», Historia, 39, I, Santiago, 2006, 177-229.

Pavis, Patrice, «Hacia el Descubrimiento de América y del drama histórico», Teatro: Revista de Estudios Teatrales, 2, Alcalá, 1992, 7-20.

Pedraza Jiménez, Felipe, Drama, escena e historia: notas para una filosofía del teatro, Granada, Universidad de Granada, 2005.

Pelletieri, Osvaldo, «Constantes del teatro popular en la Argentina», en VV.AA., Reflexiones sobre el Teatro Latinoamericano del Siglo Veinte Buenos Aires, Editorial Galerna, 1989, 171-185

Pereira, Sergio, Dramaturgia social de Antonio Acevedo Hernández, Santiago, Universidad de Santiago, 2003.

Pereira, Sergio: «La dramaturgia anarquista en Chile: ¿un discurso ideológico?», Aisthesis, 44, Santiago, 2008, 97-118.

Pérez Berrocal, Juan, Mi vida y el teatro: 1912-1981, Santiago, s.ed., s.f., 1980.

Piña, Juan, Historia del teatro en Chile 1890-1940, Santiago, RIL Editores, 2009.

Pradenas, Luis, Teatro en Chile: huellas y trayectorias siglos XVI-XX, Santiago, Lom Ediciones, 2006.

Pronko, Leonard, «El teatro político», en Adorno, Theodor [et al], El teatro y su crisis actual, Caracas, Monta Ávila Editores, 1969. 
Rodríguez, Orlando y Piga, Domingo, Teatro chileno del siglo veinte, Santiago, Lathrop Impresores, 1964.

Rojo, Grinor, «Los orígenes del teatro latinoamericano moderno: 1880-1930», Mapocho, 32, Santiago, 1992, 9-25.

Rojo, Sara, «Teatro chileno y anarquismo. Desde comienzos del siglo XX hasta el período dictatorial», Aisthesis, 44, Santiago, 2008, 83-96.

Rolland, Romain, El Teatro del Pueblo, Buenos Aires, Editorial Quetzal, 1953.

Rubio Jiménez, Jesús, «Melodrama y teatro político en el siglo XIX. El escenario como tribuna política», Castilla: Estudios de Literatura, 14, Valladolid, 1989, 129-149.

Salaün Serge, «La sociabilidad en el teatro (1890-1915)», Historia Social, 41, Valencia, 2001, 127-146.

Salinas, Maximiliano, «Juan Rafael Allende, “El Pequén”, y los rasgos carnavalescos de la literatura popular chilena del siglo XIX», Historia, 37, I, Santiago, 2004, 207-236.

Samuel, Raphael, «Introduction: Theatre and politics», en Samuel, Raphael; MacColl, Ewan; Cosgrove, Stuart (eds.), Theatres of the Left 1880-1935. Workers' Theatre Movements in Britain and America, London, Routledge \& Kegan Paul, 1985, XIII-XX.

Sánchez, Marcelo, «Racismo científico: una teoría de la evolución alternativa al darwinismo surgida en Chile», en Leyton, César (ed.), Bulevar de los pobres. Racismo científico, higiene y eugenesia en Chile e Iberoamérica, siglos XIX y XX, Santiago, Ocho Libros Ediciones, 2015, 111-122.

Sant'Anna, Vera Lúcia de Albuquerque, «Jogo de resistencia e identidade nacional: Germes do canto libertario (O teatro no Paraguai)», Mestrado em Letras Neolatinas, Faculdade de Letras, Universidade Federal do Rio de Janeiro, 1987.

Santa Cruz, Eduardo, «El nuevo arte de la oscuridad: el cine en la sociedad chilena a comienzos del siglo XX», Mapocho, 58, Santiago, 2005, 203-226.

Santa Cruz, Eduardo, Prensa y sociedad en Chile. Siglo XX, Santiago, Editorial Universitaria, 2014.

Sienna, Pedro, La vida pintoresca de Arturo Buhrle, Santiago, Imprenta Osiris, 1933.

Silva Avaria, Bárbara, Identidad y nación entre dos siglos: Patria Vieja, Centenario y Bicentenario, Santiago, LOM Ediciones, 2008.

Silva, Raquel Barroso, "“Teatro Nacional": a construção de uma ideia no século XIX», Antíteses 12, VI, Londrina, 2013, 431-455, http://www.uel.br/revistas/ uel/index.php/antiteses/article/view/15919/13572 [Consultado: [15/12/2015].

Souriau, Etienne, Les deux cent mille situations dramatiques, París, Flammarion, 1950.

Subercaseaux, Bernardo, Fin de siglo: la época de Balmaceda: modernización y cultura en Chile, Santiago, Editorial Aconcagua, 1988. 
Subercaseaux, Bernardo, «Imaginando el campo: nacionalismo cultural, política y la búsqueda de la chilenidad, 1891-1941», en San Francisco, Alejandro y Cid, Gabriel, Nacionalismos e identidad nacional en Chile: siglo XX, I, Santiago, Ediciones Centro de Estudios Bicentenario, 2010, 61-91.

Tala, Pamela, «La ambivalente representación del roto en la poesía popular chilena», Estudios Filológicos, 48, Santiago, 2011, 119-132.

Varela, Juan, Cartas Americanas, Madrid, Minuesa Editores, 1889.

Villarroel, Mónica, «El mapa del cine temprano en Chile: hacia una configuración del asombro en el contexto latinoamericano», Aisthesis, 52, Santiago, 2012, 9-30.

Villegas, Juan, Para un modelo de historia de teatro, Irvine, Ediciones de Gestos, 1997.

Ward, Guillermo, La carpa azul: texto teatral y experiencia de una investigación sobre el teatro móvil pampino, 1900-1940, Iquique, Consejo Nacional del Libro y la Lectura, 2003.

Watson, Ian, «The Social Physics of Festuge: Odin Teatret at Home», New Theatre Quarterly, 31, II, Cambridge, 2015, 179-196.

Watson, Ian, «Third Theatre in Latin America», The Drama Review, 31, IV, Cambridge, 1987, 18-24.

Williams, Raymond, Cultura: sociología de la comunicación y del arte, Madrid, Ediciones Paidós, 1981.

Yeager, Gertrude: «Elite Education in Nineteenth Century Chile», Hispanic American Historical Review, 71, Duke, 1991, 73-103. 